\title{
Chapter 5 \\ Medium-Term Revenue Strategies \\ as a Coordination Tool for DRM and Tax \\ Capacity Building
}

\author{
Wouter Lips and Dries Lesage
}

\subsection{Introduction}

This chapter will study the introduction of "Medium-Term Revenue Strategies" (MTRS) in developing countries. An initiative of the Platform for Collaboration on Tax (PCT), a network organization between the International Monetary Fund (IMF), World Bank, Organisation for Economic Co-operation and Development (OECD), and United Nations (UN). Low-income countries (LICs) and leastdeveloped countries (LDCs) face a myriad of challenges when it comes to Domestic Revenue Mobilization (DRM) for achieving the Sustainable Development Goals (SDGs). One such challenge is effective taxation, both domestic and international, which encompasses policy design-also with regard to economic and gender inequality, enforcement, and anti-abuse measures. LICs and LDCs often lack the technical or administrative capacity to realize their domestic revenue potential and as such miss out on societal investments that could help drive forward the SDGs. The SDG investment gap, or the difference between current investment and the level of investment needed to achieve the SDGs, is estimated by UNCTAD to be USD2.5 trillion. According to the World Bank, between 50 and $80 \%$ of this gap will have to be bridged with domestic government resources with the rest coming from official development aid (ODA), private funding, and private capital (Niculescu 2017).

As such, it makes sense for donor governments to try and leverage some of their official development aid (ODA) into programs that help improve taxation efforts in developing countries. Taxation has always been a part of development aid efforts. The IMF, for example, has been working on tax in developing countries

\footnotetext{
W. Lips · D. Lesage $(\bowtie)$

Department of Political Sciences, Ghent Institute for International Studies, Ghent University, Ghent, Belgium

e-mail: Wouter.Lips@Ugent.be; Dries.Lesage@Ugent.be
} 
since the 1960s. However, the issue of tax capacity building has been gaining more attention on the international agenda since the turn of the millennium. The link between taxation capacity building and development was featured prominently in all three UN Financing for Development conference outcomes ${ }^{1}$ and was also a pillar of the G20's 2010 Multi-Year Action Plan (G20 2010).

Aid and tax capacity building for DRM are one strategy to achieve that link between tax and development. Both bilateral and multilateral donors are involved in this field. Overall commitments to DRM in 2016 amounted to about USD380 million, of which USD47 million channelled through multilateral institutions (International Tax Compact 2018a). Yet, there are several issues with the fragmentation and coordination of these tax capacity building (TCB) initiatives. Because of a lack of steering, there are issues with duplication of efforts or conflictive advice when multiple organizations are active within a developing country (IMF et al. 2017). One concrete example the authors encountered during interviews was when a number of regional tax organizations were developing guidance on tax incentives independently from each other, whereas they could have pooled their efforts.

To this end, there has been a trend toward more coordination in this specific aid regime. Bilateral donors have organized themselves, together with partner countries, in the Addis Tax Initiative (ATI), a body developed to monitor the pledge of donors to double aid for DRM efforts by 2020. It is housed in Bonn where the International Tax Compact, an offspring from the 2008 Doha FFD conference, serves as its secretariat. Since 2018, the ITC also supports the Network of Tax Organisations (NTO) which brings together the regional tax organizations. On the multilateral side, there is the Platform for Collaboration on Tax (created in 2016) whose membership comprises the International Monetary Fund (IMF), the World Bank (WB), the Organisation for Economic Co-operation and Development (OECD), and the United Nations Development Program (UNDP).

These are all examples of high-level coordination, mostly among donors. While this certainly could help with the international coordination of efforts, there is still a need for a coordination mechanism at partner country level when providing aid for DRM. Not only should there be careful attention to aligning all partners in a given country; DRM aid efforts should also respect the local context in a country and make sure that the efforts match the needs of a developing country and that its program is widely supported in its local political context. Otherwise there is a distinct risk of top-down one-size-fits-all approaches to DRM that are not in the interest of developing countries. The international community recognized this hurdle, which is why the PCT developed the concept of Medium-Term Revenue Strategies (MTRS) in 2016 (IMF et al. 2016). The concept is still in an early stage but holds potential.

In this chapter, we take a critical look at the MTRS concept. After a detailed explanation of the concept, we examine what its opportunities are and which needs it can fill. We then examine the potential pitfalls of the concept. Next, we look at the evolution of the concept, how it is currently applied, and how the partners are

${ }^{1}$ Monterey, 2002; Doha, 2008; Addis Ababa, 2015. 
viewing the concept at the time of writing. Finally, we summarize our findings in a conclusion, before making some policy recommendations on how the concept could be better applied.

\subsection{What Is an MTRS?}

The purpose of an MTRS is supposed to be a holistic high-level roadmap for tax policy reform over 4-6 years. It should outline a country's revenue needs and gather political support from multiple actors in politics, civil society, and development partners. This can make it seem attractive for many countries that wish to improve their domestic revenue mobilization efforts and for developing partners as a coordination tool.

The first key component of the framework is setting clear revenue goals for a country (IMF et al. 2017). This can be expressed as a fixed amount of revenue the country wants to raise or as a desired increase of the tax to GDP ratio. It should be related to expenditure projections. Other goals can be set as well to fit the strategy. Improving the progressiveness and fairness of the tax system in a country might be one example. Reducing compliance costs and improving the perception of the tax system can be valid goals as well. These goals serve as guidelines for the other components' design and as a steering and evaluation tool for the success of the MTRS. There is a clear link here between the SDGs and the MTRS, as the set revenue goals can be tailored as a function of the public spending and investment needs in a country to reach the SDGs.

The second, and perhaps most important, component is an overview of the taxation-related reforms to achieve those set policy goals (De Mooij et al. 2018). These are broken down into three parts. The first is a reform of tax policies. This requires an extensive diagnosis of a country's current tax policy practices and will typically cover most forms of taxes: personal income taxes, corporate income taxes, property taxes, value-added or consumption taxes, and excises and duties. Countries can choose to alter the rates or bases of any of those taxes, remove or introduce exemptions and incentives, reduce thresholds, or introduce new forms of taxes. Although not explicitly mentioned, this could in theory also link to international taxation initiatives such as the G20/OECD Base Erosion and Profit Shifting (BEPS) Project and its four minimum standards. A second part under this component is tax administration reform. This is to ensure that the tax policy can be adequately implemented and to increase taxpayers' compliance, which is a core component of DRM efforts. The 2017 PCT update mentions that in many developing countries (especially LDCs), the revenue administration needs modernization (IMF et al. 2017). This can range from redesigned organizational structures to ICT improvements. However, reforming tax administrations has not always been a priority for countries in the past (IMF et al. 2017), and it is not the "sexiest" political reform. For this reason, widespread support of the revenue goals among civil society is a prerequisite for successfully achieving those necessary reforms. A last part here is 
legal framework reforms to ensure taxpayer certainty. This potentially includes an investigation of the balance between taxpayers' rights and the revenue administrations' powers.

A third component is country commitment to the MTRS. This component underscores the importance that the revenue goals and reforms are country-owned and tailored toward its specific needs. The highest levels of government, including the head of government and minister of finance, should ensure the necessary political support for a whole-of-government approach. The PCT recommends a reform management approach, including an accountable executive sponsor, steering committee, and management team, in order to oversee the process and sustain political support throughout the MTRS implementation method.

The last component of the MTRS is organizing external partners around the goals set out in the previous three components. This is the capacity building assistance component. Not only is this important to make sure all donor partners' work is coordinated, but it can also serve to ensure adequate funding for the realization of the MTRS.

The concept is still in an early phase. At the time of writing, less than 20 countries are involved in an MTRS. Only Papua New Guinea is in the early implementation phase, with all other countries still in the design or even early formulation phase:

- Early implementation: Papua New Guinea (PNG)

- Formulation support: Egypt, Indonesia, Lao PDR, Pakistan, Thailand, Uganda

- Dialogue pre-formulation: Albania, Bangladesh, Benin, Ethiopia, Georgia, Honduras, Jordan, Mongolia, Myanmar, Senegal, Uzbekistan, Vietnam (Platform for Collaboration on Tax 2019)

\subsection{The Added Value of MTRS in the Multilateral Tax Capacity Building Framework}

\subsubsection{A Crowded Global Governance Field}

Taxation is the most importance resource for state capacity. Taxation and DRM in general are also attractive concepts for donors as they promise large leverage effects of the initial aid investments, especially during a decade of increased aid fatigue due to dwindling government budgets. The relatively small amount of money flows (USD380 million) that go worldwide to aid for DRM seems puzzling in this regard. A few things help to explain this. First of all, the actual costs of technical assistance programs are relatively cheap. It mostly consists of detaching various tax experts to developing countries for training programs, policy evaluation, etc. The costs here involve flight tickets, accommodation, and so forth, but rarely entail infrastructural programs - unless IT infrastructure is part of the program, as the World Bank offers sometimes. The real costs for donor states, however, are the opportunity costs from having to miss these experts. If a country detaches one of its top transfer pricing 
experts through the OECD/UNDP Tax Inspectors Without Borders program for several months, for example, it might miss out on revenue itself. A second, more nefarious reason is that not all policymakers are so inclined to separate aid relationships from foreign policy goals. During interviews, one senior interviewee with the aid agency of an OECD country mentioned that, in the past, several members of parliament sitting on aid-related committees oppose reductions of traditional aid budgets because the latter functions as a tool of foreign policy (personal interview, 2017). A third reason is that aid budgets in many countries are traditionally earmarked for specific sectors, such as education or infrastructure, which represent vested interests in the sector. Funds for DRM work have to come from discretionary sources which tend to be rather small (personal interview, 2017).

Currently, the international framework for TCB and tax capacity building is a crowded field with many players. The first and money-wise largest group of actors providing aid for DRM are donor countries themselves. In 2016, France was the biggest provider of core DRM aid followed by the USA and the UK (International Tax Compact 2018a). Under the Addis Tax Initiative, donor countries, in 2015, pledged to double money for tax capacity support, following the Addis Ababa conference (Addis Tax Initiative 2015). This signals that TCB is gaining traction within national development agencies. However, following a significant increase in OECD DAC-reported commitments from USD175 million in 2015 to 330 million in $2016,{ }^{2}$ in 2017 the commitments were down to 192 million again (OECD 2019).

A second group of players are the multilateral institutions. In 2016, the IMF represented about $64 \%$ of the multilateral money committed to DRM efforts (International Tax Compact 2018a). Technical assistance is the biggest chunk of the IMF's Fiscal Affairs department tax work and part of its core mandate. In this context, it also manages the Revenue Mobilization Thematic Fund (RMTF) that allows donors to pool TCB resources. The IMF is also involved in the Tax Administration Diagnostic Assessment Tool (TADAT), together with the World Bank and a group of bilateral donors, and hosts its secretariat. It has also joined the International Survey on Revenue Administration (ISORA) ${ }^{3}$ with the OECD and regional tax organizations.

Another large direct technical assistance provider is the World Bank Group. The work of the WB is more aimed at long-term development and departs from a more holistic view than the IMF which works on financial-economic issues only. The World Bank tax work can, for example, be linked to health issues through technical assistance on tobacco taxes. It is also involved in more long-term investments, such as in ICT for tax administrations through its unique loan capacity as a bank (World Bank, interview 17 November 2017).

\footnotetext{
${ }^{2}$ This is based only on OECD DAC-reported statistics. The ITC DRM database is based on the same statistics but adjusted for country projects that are not mentioned in the OECD statistics. As such, it reports more money than the OECD statistics. Unfortunately, there is no 2017 entry yet in the DRM database. As such, we refer to the OECD database here, but we can reasonably expect the trend to be the same, even with the adjustments the DRM database makes.

${ }^{3}$ This database collects comparable data on the capabilities of more than 150 tax administrations.
} 
The OECD traditionally does not provide direct technical assistance and only focuses on specific issues. Its main approach is to help developing countries implement internationally agreed upon tax principles, at the moment mainly with regard to BEPS and Automatic Exchange of Information programs. The OECD offers bilateral technical assistance within the scope of specific issues, such as transfer pricing assistance. It is generally not involved in tax policy assistance, though interviewees at the OECD report demand is growing (OECD, interview 8 December 2017). The OECD also hosts Tax Inspectors Without Borders (TIWB), an initiative together with the United Nations Development Program (UNDP).

The United Nations Committee of Experts on International Cooperation in Tax Matters, which responds to the Economic and Social Council (ECOSOC), has a standard setting ambition on international taxation and publishes manuals for developing countries (sometimes financed through the International Tax Compact) on subjects such as extractive industry taxation or transfer pricing. The Department of Economic and Social Affairs (UNDESA) as part of the UN secretariat is less handson involved in TCB and only provides assistance on specific issues such as treaty negotiation. UN bodies generally do not have the ambition of holistic country assistance, rendering the UN the smallest player among the four most relevant multilateral organizations for TCB.

\subsubsection{Coordination Mechanisms}

All these different actors are involved in tax capacity building, which incites a need for at least some form of coordination. This has been recognized by those actors as well (see, e.g., IMF et al. 2017), and so we can observe two coordinative dynamics in recent years: one around bilateral donors and one for multilateral organizations.

The first centers around the Germany (Bonn)-based International Tax Compact (ITC), an organization proposed at the 2008 UN Doha Financing for Development conference whose purpose was to gather like-minded governments and multilateral organizations to find ways to strengthen tax policies in developing countries (an author's observation in Doha). In 2015, the ITC assumed the role of secretariat of the Addis Tax Initiative. The ATI is a monitoring body for the pledge of donor country to double DRM efforts by 2020. It also has a matchmaking function for convening donor and partner countries to exchange best practices and set up collaboration. The ATI currently has 44 members, i.e., 20 donor countries and 24 partner countries. There are also 16 supporting organizations (Addis Tax Initiative 2019).

Another interesting addition around the ITC is the Network of Tax Organisations (NTO), which also shares a secretariat with the ITC. It brings together nine regional tax organizations (International Tax Compact 2018b) which are increasingly getting more involved in tax capacity building as well and have a distinct advantage with regard to the local context of the countries they work for. 
The second center revolves around the four multilateral organizations, namely, the Platform for Collaboration on Tax (PCT). This too was a follow-up to an organization that came out of the 2008 UN Doha Financing for Development conference: the International Tax Dialogue (ITD), involving the IMF, World Bank, OECD, and the Inter-American Center of Tax Administrations (CIAT). This was a loose network for sharing best practices, in lieu of the proposal for an international tax organization formulated by the preparatory High Level Panel led by former Mexican President Ernesto Zedillo. It never amounted to much and is currently defunct (Lesage et al. 2010).

In 2016, the OECD, IMF, World Bank, and UN organized themselves in the PCT. The PCT got political support from G20 governments, such as Japan, which had become irritated by the increasing fragmentation of the TCB regime complex (OECD senior official, interview 8 December 2017; UNDP senior official, interview 9 November 2017). Its purpose is to strengthen international standard setting with regard to DRM, TCB, and technical assistance. Its most concrete mandate, at the behest of the G20, is to create toolkits for the implementation of the OECD's BEPS minimum standards (IMF-OECD-UN-WB 2016; IMF et al. 2017). This is to help developing countries in the BEPS Inclusive Framework with the translation of those minimum standards in their domestic policies.

\subsubsection{The Need for Country-Level Coordination}

This increase in coordination is for the most part a good thing. All these organizations feel a real demand from developing countries for technical assistance (several interviews, Washington; New York, Bonn, Paris, 2017). What is missing from this story is a method for coordinating donors at the ground level. This is an oftenoverlooked aspect in designing aid strategies. If not or improperly implemented, this can do more harm than good for the developing countries, as the administrative burden of coordination and cost of incoherency then tends to fall on developing countries (Carbone 2017; Delputte and Orbie 2014). During interviews, we also got an explicit admission from one official from a multilateral institution that "they are really good at organizing high-level conceptual conferences, but less so on the ground coordination."

A framework that puts the partner country in charge, around which the partner country and donors can organize themselves, is a necessary counterweight to all the recent coordination in the field that has been largely donor- and international organization-driven. This is where the MTRS as a coordination tool fills a clear need in the international framework for TCB. It could potentially help to ensure that the implementation of technical assistance is country-driven and bottom-up and not a top-down process that follows from demanding outcomes and results from all the coordination initiatives in the last 5 years. It sets an ambition to involve all relevant stakeholders in a developing country in a holistic policy and administration reform, with the help of donors for the technical implementation. A lot of the factors where 
the MTRS puts emphasis on come back in the recent World Bank report on how to build trust among taxpayers and increase compliance through legitimacy (Prichard et al. 2019). These are really pertinent issues in poorer countries. The MTRS thus provides an innovation that simultaneously furthers coordination on the ground in developing countries, advocates a bottom-up approach, and aims to build trust and legitimacy.

\subsection{The Pitfalls and Deficiencies of the MTRS}

Despite the innovations the MTRS seems to offer, there are a few deficiencies we can observe. These are not trivial or circumstantial and could impact its effectivness in reaching its own pre-prescribed goals. While the MTRS is a framework to address tax capacity issues in a bottom-up manner, the framework itself is a top-down construct. It comes from large multilateral organizations, which do not have a flawless track record when it comes to bottom-up policymaking in developing countries even when they explicitly set out to do so.

\subsubsection{Issue 1: Developing Countries Are Supposed to Do What Rich Countries Cannot}

A first criticism of the MTRS as a concept is that it sets ambitious goals for developing countries that most advanced industrialized countries do not aspire to themselves. A 4-6-year country-wide consensus on tax policy and revenue administration reform, coupled with revenue goals, is a tall order. Off course, such consensus makes the implementation of external tax capacity building initiatives a whole lot easier, but all those goals are politically quite contentious in nature. Tax policy reforms in Western countries are often hard-fought policies that are seldom the product of a serene nationwide debate. Instead, they are often decided upon during short opportunity windows when governing political parties try to make as much of their preferences a reality and/or quickly need to shore up their budgets. The US Tax Cuts and Jobs Act (2017) is a good example of this. It was the product of the Republican Party having a 2-year frame where they both controlled the US Congress and held the Presidency. While building society-wide consensus with all relevant stakeholders is an aspiring goal, it is somewhat strange to expect this of developing countries, when most Western countries do not seem able to adhere to this themselves. MTRS should not be an example of "do as we say, not as we do" (Hart 2018). 


\subsubsection{Issue 2: The Internationally Agreed MTRS Constrains Future Governments}

A second issue that can be raised is that MTRSs do not necessarily follow legislative cycles or government terms. This is problematic since an MTRS includes fiscal policy choices that determine the budgetary constraints of the whole of national policymaking. Suppose the new government has different revenue or policy positions. How well will this go with the donors who have organized around the MTRS? Can an MTRS bind the new government? It does not appear so, at least not in legal terms. It is not unthinkable, however, that donors will remind the new governments of the commitments their predecessors have made and realized already. This can put pressure on those new governments to keep their policies within the terms of the MTRS, even though they have not negotiated or agreed to it. This point does not necessarily amount to a criticism per se but underscores the importance of having a national process that is as inclusive as possible.

\subsubsection{Issue 3: PCT Institutions Still Need to Prove that They Are Good at "Country Ownership"}

The MTRS is a standard set by the four institutions of the PCT. This is enough to warrant scrutiny of the concept as two of those partners, the IMF and WB, have a history of damaging top-down compulsory fiscal and tax reforms in developing countries. The Structural Adjustment Programs (SAPs) of the 1980-1990s and their seemingly more benign but still contested successors, the Poverty Reduction Strategy Papers (PRSPs), remind us of a top-down approach with little country ownership and civil society participation (Lazarus 2008). The SAPs included tax programs that were based on broadening the tax base and moderating marginal tax rates (Williamson 1990) without taking into account distributive effects. This often led to regressive tax policies, following the neoliberal ideology of the Washington Consensus. Even more recent programs by the Bretton Woods institutions make little mention of the distributional effects of their proposed reforms (Damme et al. 2018). The MTRS ostensibly leaves more room for progressive tax reforms, if this is the policy goal of the country in question, but critical scrutiny of the MTRS processes and their ideological underpinnings and distributive impacts remains advisable. 


\subsubsection{Issue 4: Does MTRS Help to Bridge G20/OECD-Led International Tax Standards and Developing Country Needs?}

Fourth, the PCT's main work program is helping developing countries to implement established international tax norms. Even though the UN is on board, observers mention that this in practice means rubberstamping the OECD-developed tax standards, mainly the BEPS work program (Montes and Rangaprasad 2018). It even holds a danger that the UN ends up endorsing policy norms that were not agreed upon in the UN Committee of Experts on International Cooperation in Tax Matters or the UN Economic and Social Council (ECOSOC). Several experts have criticized how developing countries were involved in the BEPS process and the BEPS Inclusive Framework (Mosquera Valderrama 2018). It is unclear how those norms will play a role in the MTRS, but there is a possibility that the organizations involved will push the BEPS minimum standards and the upcoming BEPS IF reforms on digital economy as part of the MTRS package. One concern with the BEPS IF is that it can pressure participating developing countries into accepting international tax reforms that end up being good for international tax governance (and the position of the OECD as the central forum), but not necessarily for them. One example is the differing implementation of the principal purpose test under BEPS Action 6, which could incite negative tax competition among developing countries (Mosquera Valderrama 2019; Mosquera Valderrama et al. 2018). Another, more pressing, example comes from the ongoing efforts to address the tax-related challenges of the digital economy. The current proposals under the pillar 1 approach $^{4}$ seem to reallocate most taxing rights to large market countries such as the USA or China. It is unclear how (smaller) developing countries would benefit from a new international tax approach that is primarily sales-based (Hearson 2019). An alternative proposal made by the Group of 24 (G24), led by India, that proposes a more formulary-based approach to taxing multinationals and puts more emphasis on labor would better serve the interests of most developing countries (Chandra Prasad 2019) but is mostly sidelined by the OECD. As a tool of the PCT, the MTRS framework could become a tool through which those reforms are technically implemented which in turn could leave developing countries worse off.

\footnotetext{
${ }^{4}$ The reform package for digital economy has two work packages. Pillar 1 investigates the reallocation of taxing rights to better comply with the reality of digital business models. Pillar 2, or the GLOBE proposal, tackles a global anti-base erosion approach.
} 


\subsubsection{Issue 5: Potential Conflict of Interest Between Donor and Partner Countries' Tax Agendas}

A fifth issue is that in cases concerning DRM revenue from international taxpayers, especially corporations, there is a fundamental conflict of interest between developing countries and OECD donors which also want favorable conditions for their resident multinational companies. There is a myriad of literature on how the international tax regime is lopsided in favor of net residence countries (Cockfield 2010; International Monetary Fund 2019; Picciotto 2013), but the global tax regime is not in the scope of the MTRS. ${ }^{5}$ What should be in its scope however are the tax treaties that developing countries conclude, especially now when many of them are part of the BEPS IF whose minimum standards will be disseminated through the network of bilateral tax treaties. Research into the tax treaties of African countries shows that they sometimes literally "negotiate away their tax base" in an effort to attract foreign direct investment through tax treaties (Hearson 2018b). The most visible ways they do so are by lowering withholding taxes on capital, compared to domestic law, or by restricting permanent establishment definitions (Hearson 2018b). Tax treaties between EU countries and developing countries, for example, are among the most residence-biased in the OECD (Hearson 2018a). There are voices that question the perceived wisdom that tax treaties are beneficial for developing countries (e.g., Dagan 2000) and even the IMF prescribes caution to developing countries when signing one (IMF 2014).

This is where the MTRS conflicts with the interests of the bilateral donors. If a developing country wants to improve its tax collection capacities, then surely its corporate tax policy toward international corporations and by extension its treaties should come into scope-especially since for developing countries corporate taxation represents a much larger share of the tax mix. This follows from the fact that they collect much less personal income tax (PIT) than high-income countries (see Fig. 5.1) while roughly collecting the same level in value-added tax (VAT). So, a reduction or increase in the amount of corporate income tax (CIT) they can collect has a much larger impact on their overall revenues.

The question here is will bilateral donors allow part of their provided aid flows for tax capacity building to strengthen a developing country's capacity in international corporate taxation through an MTRS, even though this might lead to higher source taxation for multinationals headquartered in their country? Or will they focus on domestic revenue collection in the form of consumption and personal income taxes and reduce the corporate tax discussion mainly to providing tax certainty and friendly conditions (which is supposedly one of the rationales behind signing tax treaties as well) for foreign investors? The latter could follow from an ideological position that providing a business-friendly climate is a key priority of developing countries or as a quid pro for the tax capacity aid provided. The authors do not

\footnotetext{
${ }^{5}$ Although there are also capacity issues to be addressed regarding the participation of developing countries in global tax fora. See for example: Mosquera Valderrama (2018).
} 
TAX REVENUES AS PERCENTAGE OF GDP

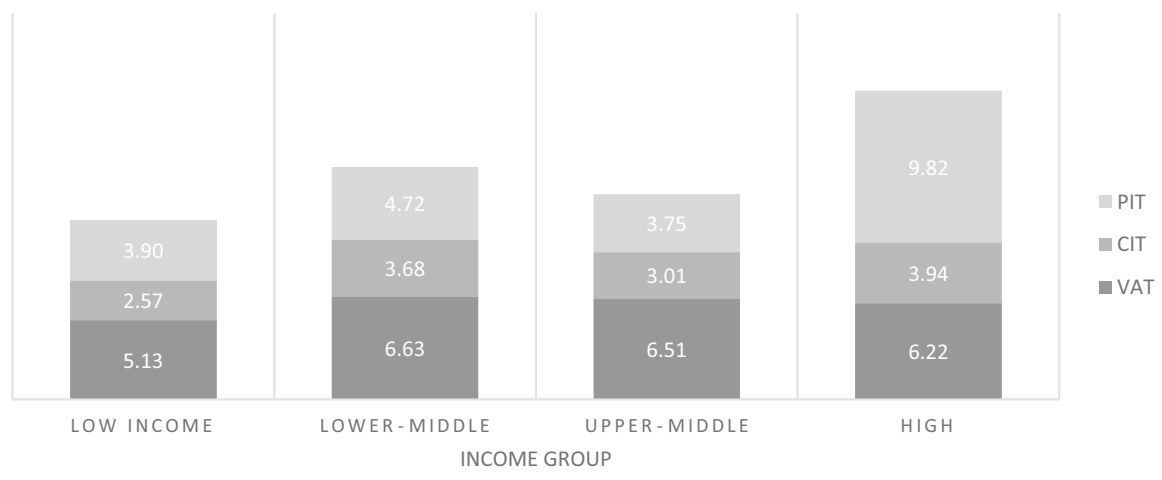

Fig. 5.1 USAID Collecting Taxes Database 2012-2013

suggest that providing medium-term tax certainty should be left out of the MTRS, as it can indeed be important to attract FDI (IMF and OECD 2019). However, focusing on tax certainty can also be a strawman that diverts attention away from antiavoidance regulation or setting corporate tax rates at a level that is beneficial for the country. If an MTRS is truly to be a country-driven exercise, then observers should be vigilant of a priori dispositions whispered in by donor countries, especially given the divergent interests between source and residence countries. This discussion also shows how important it is for donor countries in their formulation of aid for tax capacity building and MTRS bring together the expertise of their ministries of finance and tax administrations as well as the expertise and policy objectives of their development cooperation ministry as a good practice of policy coherence for sustainable development (PCSD).

\subsubsection{Issue 6: Compatibility of the MTRS with the SDGs and Sustainable Development}

Lastly, the MTRS should be designed and communicated in a way that it fully supports the SDGs and (more ambitious) national sustainable development plans. This implies that the MTRS not only helps to raise aggregate tax revenues but also enables to meet objectives on, among other things, poverty and inequality reduction, gender equality, sustainable economic development (agriculture, industry, infrastructure), and ecological sustainability. On the revenue side, the MTRS should reduce regressive and promote progressive tax policies and develop environmental taxes to steer behavior. The MTRS should also be closely tied to the spending side of policymaking for sustainable development. The PCT itself stresses the importance of situating the MTRS in this wider framework (Platform for Collaboration on Tax 2019, p. 20). The only available MTRS (Papua New-Guinea), however, presents 
itself as a quite technocratic document providing a reform agenda in which other objectives than raising revenues or the wider agenda of the SDGs and sustainable development are ignored (Papua New Guinea 2017).

\subsection{Conclusion: How to Move Forward with the Concept of Medium-Term Revenue Strategies?}

The MTRS concept is still in its early stages and it is too early to really evaluate its outcomes. We would need more ongoing strategies and testimonials from participants and stakeholders at the relevant levels on the formulation and implementation process. Nonetheless it is clear that the MTRS was born out of a real need in the crowded and complex global governance landscape for tax capacity assistance. It provides a framework for on-the-ground coordination that was missing, helping to avoid duplication of efforts, coordination, and reporting costs. In that sense, we believe MTRSs are a potentially valuable addition to the tax capacity building regime, especially since it puts the recipient country in charge.

Nevertheless, we identified several actual and potential issues with regard to the ambition, partners, legitimacy, and goals of the concept that are not fully addressed by the material that exists right now on the MTRS. We do not suggest that the people or institutions involved are not aware of these or that they are not addressed at all. In addition, the perfect should not be the enemy of the good with regard to tax capacity building, and MTRS was never intended as a panacea for all the flaws that currently exist in DRM, capacity building, or international taxation. It should be evaluated as it is an additional tool in the larger toolbox of coordination in the tax capacity building regime. However, we feel it is necessary to point to the pitfalls we described and call for scrutiny of how the concept further develops.

Both the IMF and WB are heavily invested in the concept. In October 2019, they devoted a 2-day conference to it, together with senior countries' officials and the Austrian Ministry of Finance. They discussed topics such as transitioning to an MTRS, securing whole-of-government support, setting revenue and policy goals, and securing civil society support (IMF et al. 2019). It is unclear to what extent the MTRS was discussed in relation to the broader SDG agenda. IMF head of Fiscal Policy Vito Gaspar gave a rousing keynote address in which he reaffirmed the key issue of country ownership and the case for donor coordination in a "coordinated but subordinated fashion." $\mathrm{He}$ even added "We at the IMF are enthusiastic-even passionate!—about the MTRS" (Vito 2019).

This firm investment of the Bretton Woods institutions stands in sharp contrast with the relative silence of the OECD and UN on the MTRS approach. In the latest PCT update report, it reads "[S]o far the IMF and WBG [World Bank Group] have been most involved in supporting the design and implementation of the MTRS" and further "[T] he OECD and UN have not been involved in the design or implementation of the MTRS at the country level" and "PCT partners realize the importance of 
strengthening collaboration on this front" (Platform for Collaboration on Tax 2019, p. 42). There is a suggestion that the OECD and UN are not fully on board yet/anymore. This would be worrisome and reinforce our third concern that the MTRS is a concept led by two organizations that have some baggage when it comes to country-owned reforms. It also reduces the feedback loop of designing MTRS processes in a country to IMF and World Bank work. Moreover, the exclusion of the $\mathrm{UN}$, arguably the most inclusive institution of the four PCT partners, means that one of the advantages of the PCT setup, learning and exchanging experiences between international institutions, is lost. The same goes for the OECD. By not helping to implement MTRSs at country level, the concept loses its direct link to the BEPS process, and the OECD loses out on the feedback from the countries that could tie back to the BEPS Inclusive Framework (Lips and Mosquera Valderrama 2020).

\section{References}

Addis Tax Initiative. (2015). Financing for development conference the Addis Tax InitiativeDeclaration. Retrieved June 22, 2020, from https://www.addistaxinitiative.net/documents/ Addis-Tax-Initiative_Declaration_EN.pdf

Addis Tax Initiative. (2019). Addis Tax Initiative. Retrieved November 15, 2019, from https:// www.addistaxinitiative.net/about

Carbone, M. (2017). Make Europe happen on the ground? Enabling and constraining factors for European Union aid coordination in Africa. Development Policy Review, 35(4), 531-548.

Chandra Prasad, G. (2019). 28 developing nations back India on OECD tax proposal. Retrieved November 15, 2019, from https://www.livemint.com/news/india/28-developing-nations-backindia-on-oecd-tax-proposal-11573577822211.html

Cockfield, A. (2010). Globalization and its tax discontents. Toronto: University of Toronto Press. Dagan, T. (2000). The tax treaties myth. Journal of International Law and Politics, 32, 939-2000.

Damme, L., Misrahi, T., \& Orel, S. (2018). The IMF's regressive secret. Retrieved June 22, 2020, from https://www.brettonwoodsproject.org/2008/06/art-561926/

De Mooij, R., Nazara, S., \& Toro, J. (2018). In L. Bruer, J. Guajardo, \& T. Kinda (Eds.), Realizing Indonesia's economic potential. Washington, DC: International Monetary Fund.

Delputte, S., \& Orbie, J. (2014). The EU and donor coordination on the ground: Perspectives from Tanzania and Zambia. The European Journal of Development Research, 26(5), 676-691.

G20. (2010). Multi-year action plan on development.

Hart, T. (2018). Supporting domestic revenue mobilisation: We must learn from the failures of the past. Retrieved October 17, 2020, from https://www.odi.org/blogs/10626-supporting-domesticrevenue-mobilisation-we-must-learn-failures-past

Hearson, M. (2018a). The European Union's tax treaties with developing countries: Leading by example? Retrieved October 17, 2020, from https://martinhearson.net/2018/09/27/theeuropean-unions-tax-treaties-with-developing-countries-leading-by-example/

Hearson, M. (2018b). When do developing countries negotiate away their corporate tax base. Journal of International Development, 30(2), 233-255.

Hearson, M. (2019). The OECD's digital tax proposal: Untangling the impact of 'Pillar One' on developing countries. Retrieved November 15, 2020, from https://martinhearson.net/2019/10/ 14/the-oecds-digital-tax-proposal-untangling-the-impact-of-pillar-one-on-developingcountries/

IMF. (2014). Spillovers in international corporate taxation. IMF Policy Paper. 
IMF, \& OECD. (2019). 2019 progress report on tax certainty. Retrieved November 15, 2019, from www.oecd.org/tax/tax-policy/g20-report-on-tax-certainty.htm

IMF, OECD, UN, \& World Bank. (2016). The Platform for Collaboration on Tax. Concept note.

IMF, OECD, UN, \& World Bank. (2017). Update on activities of the Platform for Collaboration on Tax.

IMF, World Bank, \& Bundesministerium Finanzen. (2019). Conference agenda: Medium Term Revenue Strategy (MTRS)-Building more effective tax systems.

IMF-OECD-UN-WB. (2016, April 7-11). The Platform for Collaboration on Tax: Concept note.

International Monetary Fund. (2019). Corporate taxation in the global economy.

International Tax Compact. (2018a). DRM database. Retrieved July 13, 2018, from https://drm. taxcompact.net/

International Tax Compact. (2018b). Launch of the network of tax organisations.

Lazarus, J. (2008). Participation in poverty reduction strategy papers: Reviewing the past, assessing the present and predicting the future. Third World Quarterly, 29(6), 1205-1221.

Lesage, D., McNair, D., \& Vermeiren, M. (2010). From Monterrey to Doha: Taxation and financing for development. Development Policy Review, 28(2), 155-172.

Lips, W., \& Mosquera Valderrama, I. (2020). Global sustainable tax governance in the OECD-G20 transparency and BEPS initiatives. In C. Brokelind \& S. Van Thiel (Eds.), Tax sustainability in an EU and international context. Amsterdam: IBFD.

Montes, M. F., \& Rangaprasad, P. (2018). Collaboration or co-optation ? A review of the Platform for Collaboration on Tax. South Centre Policy Brief, June (48), 1-4.

Mosquera Valderrama, I. (2018). Output legitimacy deficits and the inclusive framework of the $\mathrm{OECD} / \mathrm{G} 20$ base erosion and profit shifting initiative. Bulletin for International Taxation, 72(3), $1-11$.

Mosquera Valderrama, I. (2019). The principal purpose test (PPT), the BEPS inclusive framework and MLI. Retrieved November 15, 2019, from https://www.ciat.org/the-principal-purpose-testppt-the-beps-inclusive-framework-and-mli/?lang=en

Mosquera Valderrama, I., Lesage, D., \& Lips, W. (2018). Tax and development: The link between international taxation, the base erosion profit shifting project and the 2030 sustainable development agenda. UNU-CRIS Policy Paper W 2018-4.

Niculescu, M. (2017). Impact investment to close the SDG funding gap.

OECD. (2019). International development statistics.

Papua New Guinea. (2017). Medium term revenue strategy 2018-2022.

Picciotto, S. (2013). Is the international tax system fit for purpose, especially for developing countries? ICDT Working Papers, 13.

Platform for Collaboration on Tax. (2019). PCT progress report 2018-2019.

Prichard, W., Custers, A., Dom, R., Davenport, S., \& Roscitt, M. (2019). Innovations in tax compliance. Conceptual framework. World Bank Group Policy Research Working Paper, 9032.

Vito, G. (2019, October 29). Medium-Term Revenue Strategy (MTRS)-Taxation and development. Conference of "Medium Term Revenue Strategy (MTRS)—Building More Effective Tax Systems".

Williamson, J. (1990). What Washington means by policy reform. In J. Williamson (Ed.), Latin American adjustment: How much has happened? Washington, DC: Institute for International Economics. 
Open Access This chapter is licensed under the terms of the Creative Commons Attribution 4.0 International License (http://creativecommons.org/licenses/by/4.0/), which permits use, sharing, adaptation, distribution and reproduction in any medium or format, as long as you give appropriate credit to the original author(s) and the source, provide a link to the Creative Commons license and indicate if changes were made.

The images or other third party material in this chapter are included in the chapter's Creative Commons license, unless indicated otherwise in a credit line to the material. If material is not included in the chapter's Creative Commons license and your intended use is not permitted by statutory regulation or exceeds the permitted use, you will need to obtain permission directly from the copyright holder. 